\title{
$15^{\mathrm{TH}}$ ANNUAL SUMMER PROGRAM SYMPOSIUM ON QUANTITATIVE METHODOLOGY IN LIPID RESEARCH. PART IV.
}

\author{
conducted by The American Oil Chemists' Society \\ at Pennsylvania State University, University Park, August 3-7, 1964
}

Under the sponsorship of the Education Committee, N. H. KUHRT, Chairman, and GEORGE ROUSER, Program Chairman

\section{The Hydroxy Fatty Acids: Isolation, Structure Determination, Quantitation}

\author{
NORMAN S. RADIN, Mental Health Research Institute, University of Michigan, Ann Arbor, Michigan
}

\begin{abstract}
This review and commentary on quantitative methodology of the hydroxy fatty acids covers methods of isolation, structure determination, and quantitative analysis. Individual topies are: methods of liberation from bound form, separation by partition, separation by partition columns, separation by precipitation, separation by adsorption columns, separation by thin-layer chromatography, separation of homologous fatty acids, locating the hydroxyl group, characterization of the optically active hydroxyl group, locating the double bonds, gravimetric determination, colorimetric determination, gas chromatographic determination, infrared absorption, titrimetric determination, and radiometric determination.
\end{abstract}

$\mathrm{T}$ HIS GROUP OF COMPOUNDS has been reviewed fairly recently in articles by Downing (23) and Markley (73), who are to be commended particularly for their compilations of naturally occurring hydroxy fatty acids. The following review will emphasize the problems of analyzing these lipids, and will cover methods of isolation, structure analysis, and quantitative determination. It is assumed that the reader is familiar with these matters as they apply to ordinary fatty acids, and reference will be made to techniques only if they are relatively unfamiliar or if there is some question whether they can be used with hydroxy acids in unmodified form.

The abbreviations used here are: A, alcohol (ethanol); B, benzene; C, chloroform; $\mathbf{E}$, ethyl ether; $\mathrm{H}$, hexane; $\mathrm{M}$, methanol; $\mathrm{W}$, water; $n f a$, nonhydroxy (ordinary) fatty acids; and hfa, hydroxy fatty acids. Numerieal designations for fa show the number of carbon atoms and the number of double bonds. Thus 18:0 is stearic acid, 18:1 is octadecenoic acid. An $h$ is used to indicate a hfa: h18:0 is hydroxystearie acid. The position of the $\mathrm{OH}$ group, in analogy to the common system for showing the position of double bonds, is indicated by a superseript: $\mathrm{h}^{3} 16: 0$ is 3 -hydroxypalmitic acid, $\mathrm{h}^{4} 18: 1^{7}$ is 4-hydroxy-7-octadeeenoic acid.

\section{Liberation from Bound Form}

\section{Methods of Isolation}

Since the hfa normally oceur in complex lipids, as esters or amides, it is generally necessary to release them from their linkages by saponification or solvoly. sis. There is probably no complicating difference in ease of splitting such bonds, as compared with the

\section{IN D E X}

569-580 The Hydroxy Fattry Acids: Isolation, Structure Determination, QUantitation, by Norman S. Radin.

580-582 The Metabolism of Polyenolc Fatry Acids, by E. Klenk

583-587 Chemical Syathesis on $\mathrm{H}^{3}$ - AND 1-C $\mathrm{C}^{4}$-Labeled PolyUNSATURATEd Fatry Acids, by W. Stoffel
588-607 Lipids of Subcellular Particles, by Sidney Fleiseher and George Rouser

608-609 The Prostaglandins and Their Influence on Lipid Metabolism, by Sune Bergstrom

610-614 Planw Lipids, by C. Freeman Allen and Pearl Good

615-616 Human Erythrocyte Phosphoglycerides. II. Diet AND Ledithin STRucture, by J. W. Farquhar 
ordinary fa. However, almost none of the published procedures for such cleavages have been adequately examined. For any procedure it should be shown, with TLC at least, that no more of the original or a likely intermediate exists in the reaction mixture and that side products are not formed. Thus, in solvolysis (usually in M), one should look for formation of free fa. Since extraction procedures usually follow cleavage reactions, these should be tested for completeness of recovery, most easily with a radioactive fa.

The hfa often occur in amide linkage, attached to the nitrogen of sphingosine or its analogs. Since amides are particularly difficult to cleave, it is particularly important to question the adequacy of the cleavage conditions. Weighing the crude esters is certainly not a safe method of evaluation since sphingosine salts tend to accompany the hfa. For many years Klenk used Thierfelder's method: reflux $4 \mathrm{hr}$ with $10 \%$ sulfurie acid (by weight) in $\mathrm{M}$. This method apparently yielded a mixture of methyl esters and free hfa, presumably due to water-forming side reactions. Methanolysis with dry $\mathrm{HCl}$ in $\mathrm{M}$ has become more popular, probably because free fa do not contaminate the esters. We used to run this step under reflux conditions, but some loss of $\mathrm{HCl}$ takes place, and one may assume that the loss will be variable. If the reaction is run in a sealed glass tube, this is no problem.

We have recently taken advantage of the resistance of Viton A, a rubbery halocarbon plastic, to make the methanolysis more convenient (64). A methanolysis tube is made by sealing a heavy wall test tube to an $\mathrm{O}$-ring joint, and a cap is made by simply sealing off another O-ring joint. The two parts are held together, with the Viton O-ring as seal, with a suitable ball-and-socket clamp. The parts are available from Delmar Scientific Laboratories, Maywood, III. While we use the flat type of joint, the ball type should work as well; possibly the more common Buna $N$ O-rings would also be suitable. For use, the sample is added to the methanolysis tube, a solution of dry $\mathrm{HCl}(5 \%)$ in $\mathrm{M}$ is added, and the cap is clamped on. The methanolysis is carried out at $75 \mathrm{C}$ overnight. Other workers have used higher temps and shorter times, such as $100 \mathrm{C}$ for $4 \mathrm{hr}$. Cleavage of esters is, of course, somewhat faster.

It should be pointed out that heating or storing dry $\mathrm{HCl}$ in M leads to formation of methyl chloride plus water (11). Since storage for some time does not seem to spoil this reagent, it would appear that the presence of water is not as inhibiory as is generally believed, nor is the conen of the HCl at the time of use very critical. Sweeley and Moscatelli (111) have indeed started with aqueous $\mathrm{HCl}$ : they refluxed their samples 5-6 hr with concd HCl-M (1:5). Apparently methyl esters were formed. This hydrolysis mixture, because of its high water content, is not good lipid solvent.

Other workers have used aqueous $\mathrm{HCl}$ to cleave the sphingolipids, which means that very little of the sample is dissolved by the medium. Complete release of hfa and nfa was found after $2 \mathrm{hr}$ with $2 \mathrm{~N} \mathrm{HCl}$ at $110 \mathrm{C}$ in a sealed tube (90). Possibly larger samples would not be completely cleaved because the sample and acid phases are immiscible.

Alkaline cleavage of sphingolipids requires high temps. This can be accomplished by refluxing the sample in a screw cap test tube with $\mathrm{KOH}$ in propylene glycol $(6.5 \mathrm{~g}$ and $100 \mathrm{ml})$ for $30 \mathrm{~min}(61)$. This is the fastest method of releasing the ha, but polyunsaturated acids might show rearrangements. Saponification has the obvious advantage over solvolysis that nonsaponifiables can be removed by solvent partition; this is particularly useful in large scale work. Acidic cleavage converts 1-alkenyl ethers, if present, into acetals or aldehydes, which are inconvenient to remove from nfa. Probably these lipids are stable to alkaline cleavage and might give less interference.

The hfa require extra precautions, as compared to the $n f a$, in processing after cleavage. One problem arises from their low solubility in $\mathrm{H}$ or petroleum ether. If a saponification mixture in $A$ or $M$ is acidified with $\mathrm{HCl}$ and extracted with $\mathrm{H}$, enough of the polar solvent enters the upper phase to take the hfa into the H. However, when the upper phase is washed with $\mathrm{W}$ to remove $\mathrm{HCl}$, the $\mathrm{W}$ also extracts the polar solvent and the free hfa tends to preeipitate out and form an upleasant gel. For this reason, one should wash the $\mathrm{H}$ extract with W-E, W-M, or W-A or else simply use W plus E for the initial extraction. We use the latter in the propylene glycol saponification, and backwash with A-toluene-KCl (61). The KCl prevents emulsions and the toluene squeezes water out of the E extract, making drying less of a problem.

The second problem with hfa arises from the tendency of the hydroxyl group to react with the carboxyl group of the same or adjacent molecules, to form lactides or lactones. Just how serious this problem actually is has not been well determined. In the case of the 2-hydroxy acids, lactide formation is not a problem for attempts at direct synthesis have given low yields (75). It would seem wise to cool the alkaline saponification mixture while acidifying. Another approach is to precipitate the calcium salts by adding calcium chloride to the saponification mixture. The calcium salts are then converted to esters by refluxing the salts with an alcohol and acid $(24,22)$. Theoretically, precipitation of the ealcium salts allows removal of the nonsaponifiable fraction, but coprecipitation seems a likely danger and one should extract with $\boldsymbol{H}$ before adding the calcium chloride.

A third problem occurs with hfa in which there is a double bond adjacent to the hydroxyl group (in the allylic position). Such hfa readily dehydrate on heating, and acidic conditions of cleavage or esterification either produce dehydration or ether formation. Satisfactory methanolysis can be achieved by passing the glyceride esters in M through a strongly basic ion exchange column (19). The resin catalyzes the transesterification, albeit fairly slowly. It has the advantage over ordinary alkaline catalysis that there is no problem of catalyst removal.

\section{Separation of Hydroxy Fatty Acids by Partition}

Chromatography is the method of choice, but for large-scale work it might be well to try solvent partition methods. Countercurrent distribution has been used for hfa from wool fat $(45,88)$, plant cuticle (74), and fungi (8). Diamond et al. (19) have recently reported the use of this method for purification of methyl dimorphecolate $\left(h^{9} 18: 2^{10,12}\right)$, prepared from a seed oil. The distribution was carried out in separatory funnels with acetonitrile and pentane as the partitioning phases. Over $90 \%$ of the ester was recovered in a purity of $92 \%$. The actual yield, $57 \mathrm{~g}$, shows the advantage over ordinary scale chromatographic methods.

Noble et al. (88) used heptane and A-M-W as the partitioning phase. Morris et al. (80) found $\boldsymbol{H}$ and 
A-W $4: 1$ to be rather effective, more so than hexane/ acetonitrile. Furfural-H and nitromethane-H have been suggested for such separations (69).

To increase the difference in polarity between nfa and hfa, these workers have used the methyl esters rather than the free acids. Countercurrent methods tend to be sensitive to chain length, as well as the presence of the hydroxyl group, and one tends to get overlapping between short nfa and long hfa.

One can increase the difference in polarity between nfa and hfa by forming a more polar derivative of the hydroxyl group. For example, chlorosulfonic acid reacts quantitatively with hydroxy compounds in anhydrous $\mathrm{E}$, forming $\mathrm{HCl}$ and a sulfuric acid ester (7). The sulfate ester should be relatively easy to extract with a suitable alkaline water-containing solvent.

A similar derivative of the hydroxyl group is the half ester of phthalic acid (44) or succinic acid (109), formed by heating the acid anhydride and toluene with the alcohol. The resultant carboxylic acid can then be extracted into an alkaline aqueous solvent. Unfortunately for workers with long-chain hfa, such acidie derivatives form soaps in alkali and give rise to emulsion problems. However, this approach seems worth more trials, with various solvent systems and lower $\mathrm{pH}$ 's.

\section{Separation of the Hydroxy Acids by Partition Columns}

An obvious extension of liquid/liquid countercurrent systems is the partition column, in which one liqiud is rendered stationary by suitable spongy particles. Such a separation was made of the methyl esters of seed fatty aeids (28), in which the stationary phase-M-B 20:80-was immobilized with silica gel, and the esters were eluted with M-B 2:98. The nfa were well separated from the hfa, and the dihydroxy acids were eluted last, but with some trailing.

A reversed phase partition column has been described for the methyl esters of another seed oil (27). Iso-octane was the stationary phase, supported by siliconized Celite, and the moving phase was acetonitrile. Elution yielded well-separated samples of hfa, epoxy fa, and nfa. The nfa seemed to be separated into saturated and unsaturated fractions.

Such columns can also accomplish some separation according to carbon number, the resolution being suitable usually for fatty acids differing by two carbon atoms. In the case of the hfa, the interaction between hydroxyl groups interferes and it is necessary to derivatize them. The acetate esters of long chain hfa methyl esters were separated with a column in which the immobile phase, mineral oil, was held by siliconized Celite, and the individual hfa were eluted with waer-acetone mixtures (31).

An interesting study of the partition column separation of nfa and hfa describes the use of $\mathrm{W}$-acetone vs. eastor oil (38a).

The main advantage of partition columns is that they tend to allow use of relatively large samples. Reversed phase columns are of particular interest because the more polar lipids come out first. This may help yield purer preparations of hfa, since a slight amt of trailing can always be expected with any column. The disadvantages are several: many otherwise valuable solvent systems cannot be immobilized satisfactorily; gradient or stepwise elution systems are limited due to the tendency to strip the stationary phase as elution progresses; partition systems tend to be temp-sensitive and the column, as well as equilibrated solvent, may require jacketing; a number of immobilizing materials are difficult to prepare and use. I believe workers in this field are overlooking a potentially useful immobilizing material, polystyrene beads, slightly crosslinked (97). These are the beads used to make Dowex 50 , before the sulfonation (Dow Chemical Co., Midland, Mich.).

\section{Separation of the Hydroxy Fatty Acids by Precipitation}

In the special case of the $\mathrm{h}^{2} \mathrm{fa}$, chelates can be formed which are markedly more insoluble than the salts of accompanying nfa. Free acids are used for this separation since the esters do not form chelates. Lithium and magnesium chelates have been formed by adding the metal acetate in $\mathrm{A}$ to a hot ethanolic solution of the mixed fa (66). The copper chelate is a particularly suitable derivative which ean be formed by adding cupric nitrate in $\mathbf{A}$ to a solution of the fa in $\mathrm{C}(75)$ or by adding cupric oleate in $\mathrm{C}$ to a solution of the fa in absolute $\mathrm{A}(61)$.

The copper precipitation, under the latter conditions, is highly specific for hfa having the hydroxyl group in the 2-position and will give quantitative yields with as little as $0.6 \mu$ moles. However, large amts of nfa, if present, will also yield some precipitate, as will certain highly insoluble contaminants. Still, the method is very useful for large scale isolations and yields a preparation which can be purified further by reprecipitation or other means. On a small seale, it is very simple to remove excessive amts of nfa by column chromatography and then purify the polar fraction by the copper precipitation. We have found the chromatographic step necessary when working with the complex lipids of brain, not because of nfa interference but because of the presence of some unknown interfering substance (61).

The hfa are recovered from the precipitate by brief warming with coned HCl-M $1: 9$ and diluting with W-E, or by stirring for some time with aqueous $\mathrm{HCl}$ and $\mathrm{E}$. In the former method, one obtains mostly methyl ester; we treat this with coned HCl-M-dimethoxypropane for $1 \mathrm{hr}$ to convert residual acid to methyl ester (96).

\section{Separation of Hydroxy Fatty Acids by Adsorption Column Chromatography}

Adsorption chromatography readily yields separation of nfa from hfa. If the free acids are used, they may be separated with a silica gel (silicie acid) column. The nfa (and cholesterol) are eluted with $B$ and the hfa with B-E 9:1 (61). With some batches of silica gel we have found it necessary to add a little $\mathrm{E}$ to the first solvent. Preiss and Bloch (95) have performed the separation with pentane-E 85:15 for the nfa and pentane-E 1:1 for the hfa. We have used Bio-Rad Laboratories "silicic acid for lipid chromatography" and Clarkson Chemical Co. "Unisil." The latter is faster running and needs little or no pressure, but it is more expensive. Unfortunately, there seems to be a slight loss of hfa on the column.

The methyl esters of nfa and hfa can be separated with a silica gel column using pentane containing $3 \% \mathrm{E}$ and $20 \% \mathrm{E}$ (31). Another solvent system is methylene chloride for nfa esters and methylene chloride containing $3 \% \mathrm{M}$ for the hfa esters (102). B-MI mixtures have also been used (19).

The esters can also be separated with a Florisil column using $\mathrm{H}$ and H-E $9: 1$ (59). Cholesterol comes off with the hfa. Florisil, a coprecipitated magnesiasilica gel (Floridin Co., Tallahassee, Fla.), has the advantage of being much less expensive than silica gel so it is particularly suited to large scale work. 
Following the recommendation of Carroll (9), we now add water to the activated Florisil, since this allows use of lower volumes of eluting solvents. The Florisil is heated in $200 \mathrm{~g}$ batches in a Vycor beaker for $1 \mathrm{hr}$ at $600 \mathrm{C}$, cooled in a desiccator, and mixed gradually with W, $8 \mathrm{ml}$ per $100 \mathrm{~g}$. The hydrating mixture is stored $24 \mathrm{hr}$ before using, with occasional stirring. It should be discarded after 3 months. This time restriction seems to be due to sudden deterioration in the moistened absorbent (15). With this Florisil our solvents are H-B 9:1 and H-E 8:2; sphingosine is not eluted under these conditions. Carroll has performed the same separation with slightly drier Florisil, the nfa coming out with H-E 95:5 and the hfa, with H-E $75: 25$ (10).

The loading ratio which we use for both adsorbents is $70 \mathrm{mg}$ adsorbent per $\mathrm{mg}$ of adsorbing material. The substances eluted with the first solvent, in which the sample is added and the column packed, are not included in this calculation. Elution volumes are roughly $25 \mathrm{ml} / \mathrm{g}$ of adsorbent. Each batch of adsorbent must be evaluated by TLC, of course.

While Downing et al. have found alumina to cause some hydrolysis of fa esters (24), others have claimed successful separations of nfa and hfa with such columns (12). The $\omega$-hfa of sebum were separated from nfa (as the methyl esters) on alumina washed with hot $2 \%$ nitric acid (48). Hexane eluted the $n$ fa and $\mathrm{E}$ the hfa. A similar separation of carnauba wax hfa has been accomplished with petroleum ether for the nfa esters and a succession of B-A, toluene-A, and C-HOAc for the hfa esters. The alumina, after acid washing, was activated at $500 \mathrm{C}$ for $5 \mathrm{hr}$ and deactivated by storage over water (87).

When hfa occur together with a,w-dicarboxy acids, they can be separated as the methyl esters on a silica gel column, using pentane-E 90-10 for the dicarboxy acids and pentane-E 70-30 for the hfa (95). A separation of three types of methyl esters has been described: nfa, epoxy fa, and hfa $(80)$. A rather heavy loading ratio was used: about $18 \mathrm{mg}$ silica gel (Davison) per $\mathrm{mg}$ of adsorbed ester. The nfa were eluted with H-E $97: 3$, the epoxy esters, with more of the same and also H-E $95: 5$, and the hfa, with plain E. A sharper separation was achieved by using segmented columns, in which the solvent enters successively narrower column segments. We follow the recommendation of Kabara (56) and use 1-piece glass columns in which the segments are of equal length but differ by a factor of about 1.4 in inside diameter.

It is rather surprising to learn that the above separations ean be performed batchwise (80). The mixed esters were simply dissolved in petroleum ether-E $97: 3$ and mixed with silica gel, and the adsorbent was filtered and washed on the funnel. The filtrate contained almost pure nfa. Repetition of the extraction and washing of the silica gel with more polar mixtures gave rather pure epoxy fa. The hfa were not eluted but presumably could have been recovered. The filtration step, if performed with a cylindrical funnel, amounts to a column elution so perhaps the batch method is not any more convenient.

The separation of hfa from nfa has also been accomplished by first reducing the acids, as methyl esters, to diols and monohydric alcohols (24). Lithium aluminum hydride was used for the reduction, which is virtually quantitative, and the alcohols were separated with an alumina column. This separation is particularly interesting since it yielded three fraetions from wool fat: monohydric alcohols (C-B 1:2), $a, w$-diols (C-A $2: 1$ ), and $\alpha, \beta$-diols (more C-A $2: 1$ ). Additional specificity to the separation can be given by converting 1,2-diols to ketals, which are somewhat less polar. Downing et al. (24) converted the diols to hydrocarbons in good yields by reaction with iodine and red phosphorus, then with lithium aluminum hydride. This method, albeit lengthy, has the advantage that branched chain hfa are readily separated as the hydrocarbons and that GLC with the hydrocarbons is unusually efficient and especially useful for acids having very long chains.

It should be possible to shorten the above reductive approach by reducing the original hfa esters directly, without conversion to the methyl esters (47). However, the problem of removing nonsaponifiables might then be introduced. Cholesterol would probably elute with the monohydric alcohols formed from nfa. In the case of the $h^{2} \mathrm{fa}$, isolation in the form of 1,2-glycols would be useful if one wished to degrade the glycol with periodate for radioactivity work or quantitative determination.

Adsorption column chromatography has also been very effective for separating saturated from unsaturated hfa. This can be accomplished by converting the unsaturated hfa, as their methyl esters, to somewhat more polar compounds which are then readily separated with a Florisil or silica gel column. A suitable derivative is the methoxy mercuriacetate adduct, formed by warming the ester with mereuric acetate in M. After removal of the excess reagents by solvent partition, the mixture is added to the column. With Florisil (59), the saturated hfa esters are eluted with H-E 9:1 and the unsaturated esters with A-C-coned HCl 10:8:1. The strong acid regenerates the unsaturated ester and the A-C elutes it from the column. We have used this method also to separate saturated nfa and hfa, while discarding the unsaturated esters (41).

A similar separation with silica gel can no doubt be accomplished, but the published procedures appear to have been applied only to nfa esters $(34,36,52)$. The mercury adducts can be eluted without decomposition and it is possible to achieve separation according to the number of double bonds, but the yields seem to fall off after the monoenes are eluted. The mercury adducts have also been separated with alumina columns, yielding monoenes and polyenes as separate fractions (68).

The problem of separating saturated from unsaturated hfa can also be handled with silver nitratesilica gel (18). This adsorbent, by virtue of a weak, rapidly reversible reaction between silver ions and double bonds, allows separation according to the number of double bonds as well as the configuration of the bonds. No preliminary reaction is necessary, and elution is carried out in the usual way, with solvents of increasing polarity. The free $\mathrm{OH}$ of $\mathrm{hfa}$ esters does not interfere (15). We are currently using this adsorbent (25 g silver nitrate, $100 \mathrm{~g}$ silica gel) with H-B 8:2, which yields the saturated hfa methyl esters, and H-B $6: 4$, which yields the monoenoic lifa esters.

The main drawback to the silver columns is their unexpected tendency to separate esters according to their chain lengths (62). The separation is poor compared to GLC separations, but it does tend to produce overlapping fractions. The longer chain esters elute faster and we have been unable to separate $\mathrm{h} 24: 0$ from 18:1 in attempts to separate the cerebroside total fa on a single silver column. Such 
a separation has almost been achieved by Wagner et al. (116), but the procedure calls for close control of cut-off points, monitored by TLC or GLC.

An additional difficulty with the silver-containing adsorbent is the variability in quality one encounters from batch to batch. At present, the commercially available material gives poor separations and our attempts to prepare our own in large batches have also been unsuccessful. More research on how to prepare a good adsorbent of this type is definitely needed.

It should be noted that adsorption columns can often be used with unexpectedly large samples; that is, large amts of nfa can be removed from small amts of hfa with a small column. This is true only if the sample is added in the same solvent that is used to elute the nfa. Since the nfa under these conditions are adsorbed very poorly, the major load capacity of the adsorbent is usable for the more polar components of the mixture.

\section{Separation of Hydroxy Fatty Acids by TLC}

Separation of hfa from nfa by this means is fantastically simple and effective. This application of TLC for the methyl esters was first described by Vioque and Holman (115). The usual adsorbent, Silica Gel G, was used with H-E 85:15 and yielded excellent separations of dihydroxy fa, $\mathrm{h}^{6} 18: 0, \mathrm{~h}^{14} 18: 0$, $\mathrm{h}^{2} 18: 0$, and nfa. However, it should be noted that TLC yields some separation according to chain length as well as degree of unsaturation (64), so the separations of natural mixtures may not be as good as with the usual demonstration test mixtures. As much as $50 \mathrm{mg}$ of mixed esters can be separated on a single standard plate $(80)$. The proportion of $\mathrm{E}$ in the H-E mixture can be raised to $40 \%$ to give improved resolution of polar esters.

The hfa ester spots, once located, can be eluted readily from the plates and used for further separations and determinations. We like a spray of bromthymol blue in dilute $\mathrm{NaOH}$ (53), which unlike iodine does not attack unsaturated esters or give low intensities with saturated esters. The hfa esters are readily eluted from the silica gel by packing the dry powder with $\mathrm{E}$ in a small column and eluting with more $\mathbf{E}$. The indicator is not eluted.

The free nfa and hfa can also be separated by TLC by adding $1 \%$ acetic acid to the H-E mixture (71, 84). Other workers have raised the acetic acid concn to about $4 \%$ or used C-HOAc $96: 4$ (53). The acetic acid is necessary to prevent streaking of the free fa. Other solvents that have been used for the free hfa; H-EtOAc-HOAe 70:30:1 (93) and B-M-HOAc 45:8:4 (94). Recovery of the free hfa can be accomplished as above, eluting with $\mathrm{E}$.

The separation of unsaturated fa esters has been accomplished by TLC versions of the two methods deseribed in the previous section. Separation of the mercuric acetate adducts of $n f a$ was achieved with silica gel containing only $1 \%$ plaster of Paris and two successive solvents: H-E 4:1 and propanol-acetic acid $100: 1$ (72). The spots were visualized with $s$-diphenylcarbazone, a mercury detector. The unsaturated esters were recovered by shaking the powder with $M$ cone. ICl 20:1 and extracting the solution with W-E. It is likely that better recoveries would be obtained if the powder were eluted after packing in a small column.

The silver nitrate-silica gel approach has found more use because of the elimination of the mercuric acetate condensation step $(79,4)$. However, we have found as with the columns that chain length effects tend to produce overlapping of spots (mainly trailing of unsaturated nfa into saturated hfa). Perhaps the use of two successive solvents would solve the problem. In the absence of nfa or of wide variation in chain lengths, both TLC approaches look quite suitable for hfa.

The prostaglandins, a family of unsaturated hfa containing a 5-membered ring and two or three OH groups, have been separated by TLC using solvents which may be of interest for other problems (38). For the free acids, B-dioxane-HOAc 20:20:1 was used with Silica Gel G and EtOAc-HOAc-M-2,2,4-trimethylpentane-W 110:30:35:10:100 was used with silver nitrate-silica gel plates. For the methyl esters, Bdioxane 5:4 was used with Silica Gel $G$ and EtOAcM-W $8: 2: 5$ or $32: 5: 20$ was used with the silver system.

In the current enthusiasm over TLC methods, perhaps we should not lose track of older methods. Separation of the mercuric acetate adducts of nfa and hfa has been accomplished on paper chromatograms (50) and separation of nfa from hfa has been achieved with silica gel impregnated paper (99). In the latter method, the position of the hydroxyl group influenced the $R_{F}$. Silicone impregnated paper, with W-acetonitrile $1: 1$, has yielded nice separations of nfa, epoxy fa, mono-hfa, and di-hfa methyl esters (84). The same combination of compounds, as the free acids, separated well with $\mathrm{W}$-acetonitrile-acetic acid. Mineral oil impregnated paper has yielded similar separation, including separation of homologs and saturated and unsaturated fa (106).

\section{Separation of Homologous Hydroxy Fatty Acids}

Partial separations of the hfa, in the form of their $O$-acetyl derivatives, have been made with a reverse phase liquid column (31). In this system, as in similar systems, the separations are adequate for 2 carbon steps but not for adjacent or unsaturated homologs.

GLC is the method of choice, just as with the nfa. The first such separation was accomplished with the methyl esters after etherification of hea with methyl iodide and silver oxide (59). It had previously been found that poor recoveries and poorly shaped peaks were obtained if the hydroxyl group was not masked. The ether formation, ordinarily considered a low-yield reaction, was pushed to completion by using the methyl iodide as solvent, by adding several portions of silver oxide, and by refluxing $3 \mathrm{hr}$. More recently, the ether has been made by reaction with methyl iodide and sodium hydride in dimethylsulfoxide $(43,119)$. This reagent system appears to be much faster but its utility has not yet been conclusively documented. The ether esters can be separated by GLC in the same way as nfa esters. Because of the methoxyl group, they come off the chromatograph roughly 1.5 C-numbers after the corresponding nfa ester.

The $\mathrm{OH}$ group of hfa ean also be masked by acetylation. We adapted the method of Hagemeyer and Hull $(40,61)$, reaction with isopropenyl acetate (the acetate ester of acetone enol; Eastman Organic $\# 6324$ ). A few $\mathrm{mg}$ of the methyl hfa ester are deposited in a short conical test tube made from a $13 \times$ $100 \mathrm{~mm}$ screw-cap culture tube, and $50 \mu \mathrm{l}$ of isopropenyl acetate-sulfuric acid $500: 1$, freshly mixed, is added. The tube is capped and heated in a $60 \mathrm{C}$ bath for $30 \mathrm{~min}$, then extracted with $0.3 \mathrm{ml} \mathrm{W}$ and $0.3 \mathrm{ml}$ toluene-E $1: 1$. The extraction step hydrolyzes the excess reagent and removes the sulfuric acid, acetic acid, and acetone. The upper layer is exposed to a few grains of potassium carbonate to remove 
residual water and acid and the esters are analyzed by GLC.

The acetylation method is faster than the methylation method but the GLC separations seem distinetly inferior and a higher column temp is necessary. However, if the hfa are to be isolated from the gas chromatograph and degraded chemically, the acetate derivative is preferable as it is much easier to hydrolyze.

We have shortened the acetylation method recently (15) to save the trouble of washing out the acid catalyst. The sample is heated as above with $0.4 \%$ toluenesulfonic acid in iso-propenyl acetate, then left with a crumb of potassium carbonate for $15 \mathrm{~min}$. The supernatant solution is injected into the gas chromatograph directly, without further treatment. There is an unknown soluble byproduct formed from the reagent, so we have inserted a glass liner tube with a glass wool plug in the injection oven of the chromatograph. The tube is removed periodically and washed out.

In a recent paper on GLC of the hfa (90), O'Brien and Rouser have deseribed the application of a FritzSchenk acetylation reagent (30), pyridine-acetic anhydride-toluenesulfonic acid. The reaction is accomplished in $3 \mathrm{~min}$ at $100 \mathrm{C}$ and the acetate is recovered by adding $W$ and $H$. The ester solution is evaporated to dryness, then evaporated several times after additions of $\mathrm{E}$ (until the pyridine can no longer be smelled).

Apparently it is not necessary to modify the $\mathrm{OH}$ group for all gas chromatographic conditions. O'Brien and Rouser state $(90)$ that saturated hfa shorter than 20 carbons need not be acetylated. Morris et al. state (83) that $h^{2} 18: 0, h^{12} 18: 0$, and methyl ricinoleate need not be acetylated. Preiss and Bloch (95) have isolated $h^{18} 18: 0$ and $h^{17} 18: 0$ as the methyl esters, using silicone XE60. Morrissette and Link (85) have obtained fine peaks with $\mathrm{h}^{12} 18: 0$ and even dihydroxystearate, using the polyamide, Versamid 900. Gerstl et al. (33) analyzed brain $h^{2}$ fa up to $h 26: 1$ without derivatizing. Miwa et al. (77) have compared the retention times of hfa (mono- and dihydroxy) with those of other fa on Apiezon $L$ and Resoflex 446. Carroll (10) has used SE-30 for the $h^{2}$ fa methyl esters up to $h 24: 0$ but found it necessary to use the methyl ethers when polar packings were used. The ethers ran only slightly faster than the free alcohols with SE-30.

Perhaps the use of all-glass columns, well siliconized, and lightly loaded packings obviates the need to mask the hydroxyl group. However, the advantage gained by decreasing the mol wt of the hfa may be lost, in terms of retention times, by the slowing effect of the free hydroxyl group.

Not all hfa can withstand the rigors of GLC. When the hydroxyl group is close to a double bond, dehydration takes place $(82,83)$ and acetylation does not prevent this. In this study, the packing was $15 \%$ polyester; it may well be that the degradation problem could be overcome by reducing the packing concn somewhat. Also, the flash heater temp can be reduced somewhat if a temp program is used for the column.

We have made some tests with the trimethylsilyl ethers of hfa (64). They were readily formed with trimethylsilyl chloride and hexamethyldisilazane by the method of Sweeley et al. (110) and TLC showed the reaction went to completion. There was no particular improvement in retention times or peak sharp- ness as compared with the acetate esters, nor was there a saving in processing time, since we evaporated the silylating reagents off with nitrogen and extracted the ether esters with $H$. For preparative scale GLC isolations it would seem wise to reduce the amts of the excess reagents injected into the chromatograph. Perhaps it is easier to regenerate the hfa after isolating the individual ether esters by GLC, for the ethers are quite unstable in acid. In a recently published abstract, Wood et al. (118) state that the trimethylsilyl ethers are eluted much faster than the acetate esters.

The trifluoroacetate derivatives of the hfa do not seem to have been investigated yet. It is likely that they would show shorter retention times. However, it appears to be difficult to obtain satisfactory trifluoroacetic anhydride.

Another approach to GLC isolations of the hfa, suitable for the 2- or 3-hydroxy acids, is via the reduction to diols and conversion to the acetonyl ketals (22). The hfa esters are reduced with lithium aluminum hydride, and exposure to acetone-sulfuric acid for $2 \mathrm{hr}$ yields the ketals. This type of derivative is readily regenerated to diols for further degradation.

In the special case of the $\mathrm{h}^{2} \mathrm{fa}$, one can decarboxylate the free acids with lead tetraacetate, a very specific reagent for glycols and $\mathrm{h}^{2} \mathrm{fa}$, and analyze the resultant aldehydes by GLC $(60)$. This method has the desirable feature of lowering the retention times considerably but the aldehydes cannot be stored very long prior to GLC. However, now that liquid nitrogen refrigerators $(-196 \mathrm{C})$ have become practical, the way is no doubt open to indefinite storage of the aldehydes.

Standards for GLC identification of hfa are rather scarce. A crude preparation of $h^{2} 18: 0$ acid is available from K \& K Laboratories (Plainview, N. Y.), which also sells "1-hydroxypentadecanoic acid-15" and 9 (10) -hydroxystearic, $\mathrm{h}^{12} 18: 0$, and $\mathrm{h}^{2} 26: 0$ acids. Applied Science Laboratories (State College, Pa.) sells more highly purified hfa: $h^{2} 14: 0$ and $h^{12} 18: 0$ acids and their methyl esters. Lachat Chemicals (Chicago, III.) offers rather pure $h^{2} 26: 0, h^{12} 18: 0$, and ricinoleic acids. The 2 -hydroxy fa are simple to make, by successive reaction with thionyl chloride, bromine, and aqueous $\mathrm{KOH}(86,103)$, and one can make an extire homologous series by starting with a mixture of $\mathrm{nfa}$. Of course one can always use a natural preparation of hfa if the major peaks have already been identified by someone else.

\section{Methods of Structure Determination}

\section{Locating the Hydroxyl Group}

If the $\mathrm{OH}$ is in the 2-position, it should be possible to precipitate the copper chelate, as described earlier. The precipitate is a very pale blue, whereas nfa or fa in which the $O H$ is further from the $\mathrm{COOH}$, yield a deep blue copper salt under ordinary conditions of precipitation.

If there is no confusion arising from homologs, one can show by the $R_{F}$ on TLC (113) or silica gel paper (99) chromatography that a $2-\mathrm{OH}$ or $3-\mathrm{OH}$ fa is present. Since the differences are not very great, a closely similar standard is necessary. If the hfa is reduced to a 1,2-glycol, it can be identified as one by the periodate reaction, which yields formaldehyde, a readily identified product. If the resultant glycol forms an acetonyl ketal, the hfa must have been a $h^{2} f a$ or $h^{3}$ fa.

If, in the course of the manipulations, the hfa has formed a lactone, one may assume the $\mathrm{OH}$ group is 
in the 4-or 5-position. Lactonization may be detected by loss of the $\mathrm{OH}$ peak from the IR spectxum, or by change in adsorption properties (TLO, ete.).

3-Hydroxy acids react specifically with coned sulfuric acid to produce a colored solution with maximum absorption at about $235 \mathrm{~m} \mu$ (107). The method is suitable for quantitative determination but is said to be only partially satisfactory for acids with more than $6 \mathrm{C}$ atoms (115). A similar reaction is given by 2,3 -unsaturated acids. When $\mathrm{h}^{3}$ fa are oxidized to $\beta$ keto acids, decarboxylation takes place readily, so isolation of a nonacidic ketone is strong evidence for the 3-substitution. 3-Acetoxy fatty acid esters undergo $\beta$-elimination on exposure to anhydrous alkali and form $a, \beta$-unsaturated acids (70a). These can be identified by their ultraviolet absorption.

If the keto acid formed by oxidation of a hfa yields a positive iodoform reaction, one can assume the $O H$ was on the second carbon from the methyl end. Iodoform should be rather simple to detect by GLC, especially with an electron capture detector.

The dinitrophenylhydrazones of certain types of carbonyl compounds form specifically colored bands on magnesia columns (102a) and it may be presumed that the same is true even if a carboxyl group is present. The hydrazones of methyl ketones are gray, saturated aldehydes are tan, 2-enals are red, and 2, 4-dienals are lavender. Probably the corresponding ketones give similar colors as the aldehydes.

GLC offers a more general method of locating the OH group, provided a suitable collection of authentic samples is available. In the study by $O^{\prime}$ Brien and Rouser (90), all the isomers of h16:0 (acetates and free $\mathrm{OH}$ ) were examined with several packings and a rather sensitive relationship was found between $R_{t}$ and $\mathrm{OH}$ position. The isomers $6-\mathrm{OH}$ to $12-\mathrm{OH}$ could not be separated, however.

There appear to be two general methods for locating the OH group by chemical degradation. One example is seen in the analysis of butolic acid, a shellac component (12). Chromic anhydride in acetic acid oxidized the hfa to a keto acid (methyl ester), which was then converted to the oxime and heated at $100 \mathrm{C}$ with sulfuric acid. The last step results in a Beckmann rearrangement, with formation of two isomeric amides. The amides were hydrolyzed and the two acids formed, $9: 0$ and adipic acid, were identified by GLC. From this evidence it was concluded that butolic acid is $h^{6} 14: 0$. As an extra check, one can characterize the amine formed from hydrolysis by means of GLC.

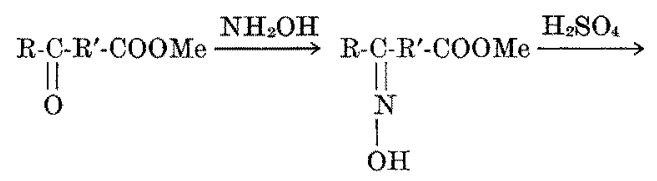

$$
\mathrm{R}-\mathrm{NH}-\|_{\mathrm{O}} \cdot \mathrm{R}^{\prime} \cdot \mathrm{COOH}+\mathrm{R}-\mathrm{C}-\mathrm{NH}-\mathrm{R}^{\prime}-\mathrm{COOH} \stackrel{\mathrm{H}}{\stackrel{\mathrm{H}}{\mathrm{O} O}}
$$

$\mathrm{R}-\mathrm{NH}_{2}+\mathrm{HOOO}-\mathrm{R}^{\prime}-\mathrm{COOH}+\mathrm{R}-\mathrm{COOH}+\mathrm{H}_{2} \mathrm{~N}-\mathrm{R}^{\prime}-\mathrm{COOH}$

The other degradative method involves direct oxidation of the hfa to mono- and dicarboxylic acids. Two sets of acids can be formed, depending on which side of the $\mathrm{OH}$ group chain cleavage takes place. A more coned solution of chromic acid and a longer oxidation time are used. The fa can be identified by GLC. This method has been used to characterize $\mathrm{h}^{18} 18: 0$ and $\mathrm{h}^{17} 18: 0$ (95). In the case of the latter isomer, of the two possible dicarboxylic acids only the
$\mathrm{C}_{16}$ acid was found. Permanganate has also been used for such a degradation $(6,51)$.

With either degradative method, one can anticipate difficulties in identifying the shorter acids. The shorter acids tend to be lost by volatilization, especially after esterification, and special precautions are needed to minimize this effect. One can precipitate the acids as the silver salts and convert them to esters with methyl iodide-pentane in so concd a solution that evaporation is unnecessary before GLC (32). Alternatively one can extract the acids with $\mathrm{E}$ and remove the solvent under controlled conditions which yield little loss of the shorter acids (98). The acids are then analyzed by GLC as the free acids. It is possible to esterify the acids before GLC without serious loss by the method described in the next section. Incidentally, a large assortment of dicarboxy acid standards is available from Lachat Chemicals, Ine.

A recently described method which might be suitable for identifying the shorter acids involves steam distillation, neutralization with $\mathrm{NaOH}$, and analysis of the dried salts by flame ionization GLC (114). The sodium salts are first treated with a mixture of formic acid, xylene, and carbon disulfide and the entire mixture is injected. The formic acid converts the salts to free acids and the xylene acts as internal standard.

Some ambiguity can arise from oxidative cleavage since overoxidation tends to form small amts of shorter fa and possibly polar byproducts. The overoxidation products can be distinguished from legitimate products of isomeric hfo in the original sample by simple arithmetic and area measurements of the various GLC peaks. Each hfa isomer should produce equimolar amts of degradation products, mono- and dicarboxylic acids, if the original sample was homogeneous with respect to chain length.

The presence of double bonds in a hfa makes the degradative reactions for $\mathrm{OH}$ location more difficult. It is probably best to hydrogenate part of the sample. In the fortunate case of dimorphecolic acid (108), the hydrogenation yielded a previously described hfa, $h^{9} 18: 0$, which was identified from its IR spectrum. In this example, it was shown that the hydroxyl group in the original acid was in an allylic relation to one of the two donble bonds by the ready dehydration on heating with acetic acid. A conjugated triene was formed, identified spectrophotometrically.

Another type of diffieulty can arise when two or more OH groups are present. This can produce quite a mixture of dicarboxylic acids if the dichromate oxidation is carried out to the chain cleavage stage. If the oxidation is adjusted to yield polyketo acids, it may be possible to characterize these. A fatty acid possessing two ketone groups in a 1,4 relationship will yield a pyrrole on heating with ammonium acetate (17). At least one can reduce the keto acid by a Wolff-Kishner reaction to form a $\mathrm{nfa}$, which can then be characterized and checked for the presence of homologs.

(One can also characterize the carbon chain directly with the hfa by reducing it with red phosphorous and $\mathrm{HI}$ (113) or by dehydrating it with $\mathrm{P}_{2} \mathrm{O}_{5}$ in $\mathrm{B}$ (57a) and then hydrogenating it.)

In the special case where two adjacent OH groups are present, one can apply the convenient periodate cleavage reaction and study the two products. Periodate has only a slow effect on 2-hydroxy fatty acids. [Incidentally, periodate reactions can be followed quantitatively at very low levels by direct spectro- 
photometry (20).] Additional information about the configuration of adjacent $\mathrm{OH}$ groups can be obtained by treatment with acetone plus a trace of acid: only cis-glycols react to form the isopropylidene derivative. An example of this application may be seen in a study of isomers of 9,10,12-trihydroxystearic acid (27).

The reaction of acetone with a free 2 -hfa can lead to confusion, as the $\mathrm{OH}$ of the carboxyl can react to form a 1,3-dioxolan-4-one (26).

IR spectrophotometry of hfa can be helpful in locating the hydroxyl group. A recent study (and list of earlier studies) gives spectral details of some isomeric hydroxystearie acids and their keto, methyl, and acetyl derivatives (65). Good reviews on fatty acids and their derivatives by $O^{\prime}$ Connor $(91,92)$ give additional references. Even without standards, one can sometimes determine the length of the unsubstituted portion of a hfa by counting the progession bands in the $7.4-8.5 \mu$ region. The methyl ester of

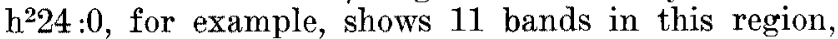
corresponding to $2 \times 11$, or 22 carbon atoms $(64)$. We have had difficulty in getting these bands with certain spectrophotometers, probably because the beam intensity causes the sample to melt. The bands show up only in solid samples.

If the hfa has formed a lactone, the position of the OH may be deduced from the position of the IR peak for its lactone carbonyl group $(91,94)$. $\gamma$-Lactones have the peak at about $5.65 \mu$ and $\delta$-lactones at about $5.75 \mu$.

Mass spectrometry is probably an excellent method of structural analysis for the hfa $(5,100)$, but little has been published so far and few suitable mass spectrometers are as yet in use. Not only does this technique give us the weights of the various degradation products formed from the sample, but it can be applied to the separated molecules coming from the outlet of a gas chromatograph.

\section{Characterization of the Optically Active Hydroxyl Group}

In most cases, the presence of the $\mathrm{OH}$ group in a naturally occurring hfa means that the compound is a member of the D or L series. The configuration of the $O H$ group is considered with respect to the carboxyl group, disregarding the intervening methylene groups; that is, the hfa is compared with $\mathrm{D}$ - and L-lactic acids.

A general approach for relating the configuration of an unknown substance to that of a known substance involves measuring the optical rotations with a variety of derivatives. Parallel changes in direction of rotation can generally be assumed to indicate identity in configuration. Such a comparison was made with the $\mathrm{h}^{2} \mathrm{fa}$ of wool fat, using the free acids, methyl esters, and sodium salts in various solvents (46). Comparison standards were synthesized from L-malic acid by an elegant series of steps: acetylation to form the 0 -acetate, half-esterification to form the a-ethyl ester, and anodic coupling (Kolbe reaction) with a series of $n f a$ to form the $h^{2}$ fa esters of the $\mathrm{L}_{\mathrm{L}}$-series. By such comparisons, it was shown that the wool fat hfa are in the D-series. A similar study with brain hfa yielded the same conelusion (76). The comparison standards here were D-mandelic acid, D-lactic acid, and D-hexahydromandelic acids.

The anodic coupling reaction is suitable for relating other types of hfa, since one can start with a naturally occurring (asymmetric) hfa and couple it with a suitable dicarboxy half-ester. Serck-Hannsen (104, 105) has made elegant use of the coupling reaction in order to determine the configuration of ricinoleic acid. First, the half-ester of 3-hydroxyglutaric acid was made and acetylated. This was resolved by crystallization with an active base and coupled with hexanoic acid to form the active $h^{3} 9: 0$. This acid is also formed by oxidative cleavage of ricinoleic acid, $h^{12} 18: 1^{9}$. As a further check the $h^{39}: 0$ was acetylated and coupled with the half-ester of hendecanedioic acid to form the reduction product of ricinoleic acid, $\mathrm{h}^{12} 18: 0$.

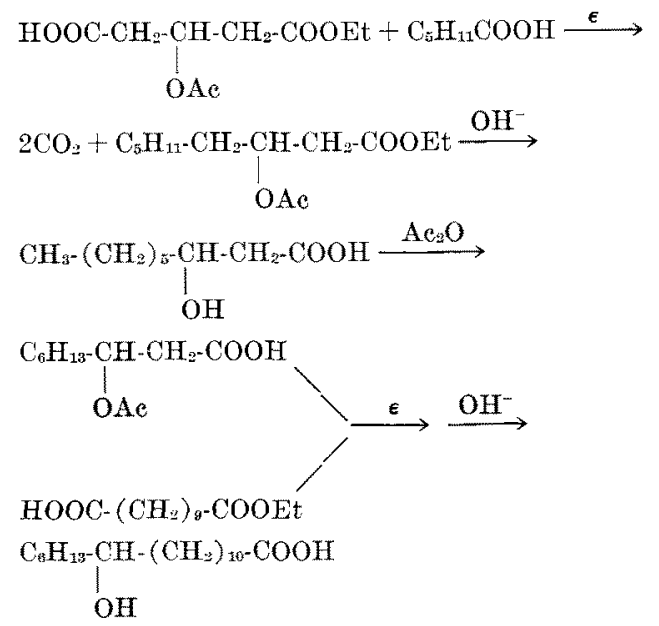

The reader faced with the problem of optical isomers should also consult the papers by Lemieux (70), which deal in great detail with polyhydroxy acids and contain many reactions of structural interest. The study by Gorin et al. (37) of $h^{17} 18: 0$ and $h^{17} 18: 1$ is also instructive.

The recent technical advances in measuring optical rotations at different wavelengths make this approach potentially very useful. The xanthates of hfa show a strong Cotton effect which can be used to determine their absolute configurations (21).

\section{Locating Double Bonds in Hydroxy Fatty Acids}

The double bonds in hfa are generally located as with nfa, by ozonolysis or permanganate cleavage. An efficient and sensitive method of ozonolytic analysis is described here (63). The unsaturated hfa of brain were converted to the methyl ether esters, the monoenes were isolated, and the individual homologs were isolated by GLC with a silicone SE-30 column. Each compound, about $2 \mathrm{mg}$ in $0.6 \mathrm{ml}$ of C-M $1: 2$, was treated with ozone made by a simple generator (62). The ozonide was cleaved with performic acid and the resultant acids taken up in $0.5 \mathrm{ml} \mathrm{E-M} 9: 1$ and anhydrous sodium sulfate. The desiccant removed the water from the mixture. Most of the dried solution was then placed in a micro gas-bubbler and diazomethane was slowly bubbled in, carried by a stream of nitrogen. When methylation was complete (sudden appearance of yellow color), the excess diazomethane was removed with additional nitrogen and aliquots of the solution were studied by flame ionization GLC. In order to keep the mono- and dicarboxy esters on the same chromatogram, a temp program was used, starting at room temp and going up to $210 \mathrm{C}$. Acids up to 26 carbon atoms were analyzed in this way.

This method of analysis has a number of good features: (1) It avoids evaporation steps and therefore minimizes loss of short acids. Even butyrate is recovered in reasonable yield. (2) It is not necessary to separate the degradation products into mono- 
and dicarboxy acids, as is usually done. By analyzing the two groups of acids together, one can more readily quantitate their peak areas and determine whether a given peak is due to overoxidation or to the presence of a fa isomer with a double bond in another position. (3) Unlike the reductive cleavage methods, where aldehydes and aldehyde esters are formed from the ozonides, the products are stable and there is less difficulty in obtaining standards for GLC identification. (4) No complex apparatus or unusual catalyst is needed. As with all oxidative degradations, some byproducts are formed and one must examine the resultant esters with two types of GLC columns in order to quantitate the various peaks. This question is particularly important when the original compound is a mixture of isomers. We found 3 to 4 isomers in each brain monoenoic hfa.

The need for standard methoxy dicarboxy esters for GLC comparison can be a problem. We made the 2-methoxy compounds by mixing several dicarboxy acids, brominating with only one mole of bromine, hydrolyzing to the hfa, and methylating. At each stage the products were purified by copper precipitation or Florisil columns and examined by TLC.

The effective periodate-permanganate method of splitting double bonds has also been applied to hfa (37). A yeast monoenoic hfa was eleaved in this way, without protecting the $\mathrm{OH}$ group, and yielded nonanedioic acid and a $h 9: 0$. The acids were separated by preparative GLC in the form of the butyl esters, since the methyl esters were poorly resolved. Finding nonanedioic acid showed the double bond was in the 9-10 position. Identification of the $h 9: 0$ as $h^{89: 0}$ was made by oxidation to the keto acid and comparison with the known keto acid.

Ozonolysis can also be applied to hfa without protection of the $\mathrm{OH}$ group. Reductive eleavage of the ozonide yields a hydroxy aldehyde which might be useful for further characterization. Dimorphecolic acid was treated this way, after reduction of the ester to an alcohol (lithium aluminum hydride). Reductive ozonolysis yielded hexanaldehyde and a dihydroxyaldehyde which reacted with dinitrophenylhydrazine to form an osazone (108). The osazone formation showed that the $O H$ of the original acid was adjacent to one of the double bonds and that it was between this double bond and the carboxyl group.

While the configuration of a double bond can generally be identified as trans by the absorption peak at about $10.3 \mu$, there are cases in which this peak is split or assignable to another function. This problem arose in the identification of the hfa of royal jelly, 10-hydroxydec-2-enoic acid (2). This acid showed a peak at 10.1 , but its hydrogenation product showed a similar peak at $10.2 \mu$. The double bond was established as trans by means of nuclear magnetic resonance analysis $(3)$.

Cis double bonds show a small peak at $6.1 \mu$ and either type shows a small, sharp peak at $3.3 \mu$, whose detection requires an instrument with good resolution in this region.

\section{Quantitation of the Hydroxy Fatty Acids}

\section{Gravimetric}

This approach can obviously be applied to any sample of pure hfa isolated by one of the methods described in the first section of this article. As other methods were developed, this approach lost favor with the analytical chemist. However, certain recent developments make it once more very attractive. First, the efficiency of separation that can be achieved with modern adsorbents makes it relatively easy, in many cases, to isolate very pure hfa. The blanks from these adsorbents are generally very small. Second, the invention of the Cahn Electrobalance (Cahn Instrument Co., Paramount, Calif.) has made extension of gravimetry to the milligram level very easy.

The usefulness of the Electrobalance has recently been augmented for the lipid chemist by the introduction of small Teflon weighing cups (49) which hold $2 \mathrm{ml}$. Samples of $1 \mathrm{mg}$ or less can be weighed very accurately and quickly. One can evaporate a chromatographic fraction to dryness in a small flask, then transfer the hfa with three 1-ml portions of benzene, letting the solvent evaporate in the cup between rinses (16). Use of a more volatile solvent leads to unpleasant creeping.

Since one can readily purify several $\mathrm{mg}$ of hfa on a single TLC plate and elute the material from the powder, combination of the two techniques may be the answer to many analytical problems. Unlike other general methods of determining fa (titration, charring, liquid/liquid partitioning with eopper or dyes, ete.), the gravimetric method gives samples which can be readily processed further.

Gravimetric determination of decigram quantities or more can lead to high values because of the difficulty of removing solvent. While classical organic chemistry offers reasonable methods of drying, we would like to recommend lyophilization for solid lipids. We routinely evaporate the samples to a syrup by rotary vacuum distillation, then displace the remainder of the solvent with benzene by addition of benzene and further evaporation. A little more benzene is added and the sample is frozen and lyophilized in the usual way. This method gives a fluffy product which is free of solvent, and is reasonably fast and safe from the dangers of splashing resulting from attempts at complete drying by vacuum evaporation.

\section{Colorimetric}

In the case of the $h^{2}$ fa, one can precipitate the copper chelate and measure the amt of copper in the chelate. This can be done simply by dissolving the chelate in a chromogenic chelator, diethyldithiocarbamic acid (disodium salt), which forms an intense color with copper ions (61).

There are a number of methods for colorimetric determination of hydroxy compounds which do not seem to have been tried with hfa but which should work. A sensitive and reasonably rapid method involves acetylation, hydrolysis of the excess acetic anhydride, treatment with hydroxylamine to form the acethydroxamate, and color formation with ferric perchlorate $(39,78)$. Only about $3 \mu$ moles of hydroxy compound are needed and all the steps involve simple additions of liquid to a container.

Another method involves the reaction of the hydroxy compound with 3,5-dinitrobenzoyl chloride in pyridine, partition between $\mathrm{H}$ and aqueous $\mathrm{HCl}$ to remove the reagents, and color formation by addition of dimethylformamide and propylenediamine (54). In another version, for hydroxysteroids, the color is developed in acetone-aqueous $\mathrm{KOH}$ (13). The reaction is very sensitive. A similar approach is the formation of the $p$-nitrobenzoyl ester, removal of the excess reagent, and determination of the aromatic ester by its ultraviolet absorption (103a). 
If the hfa is separated as the free acid from its contaminants, one has available a variety of methods for determining the carboxyl group. The transfer of cupric ions into an organic phase is the basis of a sensitive, elegant method for nfa (25), but it remains to be seen whether hfa do not give trouble because of solubility differences. If the hfa is separated as the methyl ester from other esters, one can use the hydroxylamine-ferric ion method. In our experience with $h^{2} f a$, this reaction requires extra time as compared with the nfa but can be made reliable by using a controlled temp (35).

It is possible to oxidize secondary alcohols to ketones with chromic acid, then to determine the ketones with dinitrophenylhydrazine, using $\mathrm{KOH}$ to develop the color (14). The oxidant must be removed with hypophosphorous acid before forming the hydrazone. It would be nicer if one could determine the amount of reduced dichromate colorimetrically, but I suspect that side reactions would make this impractical.

\section{Gas-Liquid Chromatography}

The hfa seem to behave much like the nfa in GLC with thermal conductivity detectors. In the case of argon ionization detectors, the hfa acetates give only one-half the response of nfa $(90)$. Unfortunately, mixtures of hfa for testing an instrument's ability to quantitate are not yet available.

Other aspects of hfa GLC are discussed in an earlier section, under Isolation Methods.

\section{IR Absorption}

Quantitative analysis by IR spectrophotometry is not yet a popular method, but it should be seriously considered for the hfa in view of the distinct and fairly strong $\mathrm{OH}$ peak at around $2.9 \mu$. Generally the $\mathrm{OH}$ of carboxyl groups interferes so it is better to work with the hfa esters. The $\mathrm{OH}$ groups of water, alcohols, and peroxides also interfere. Almost any solvent can be used to dissolve the hfa ester. The solvent is placed in the reference cell and the solution in the other cell, and the spectrum is recorded at a slow scanning speed in the region of the $\mathrm{OH}$ peak. Details of calculation, which are a little different because the sample has some basal absorption at every wavelength, may be found in books on IR work.

There are a number of good reasons why this approach is not used by as many people as own IR spectrophotometers. At best, high precision cannot be obtained with present day instruments. The method is hardly as sensitive as most methods, in terms of sample size. Hydroxy compounds tend to show effects of association, depending on the solvent; that is, the specific absorption depends on the conen. Pyridine has been used to counteract this effect $(57)$. The sample temp (which rises with time) affects the sample's absorptivity. Thermostatic cells are now available, but their effectiveness is yet to be determined.

The value of the approach lies in its simplicity: preparation and purification need only be minimal. Moreover, a continuous flow cell could be used to follow changes in a stream. IR determinations of hfa have been described by Thomas (112) and Ahlers and MeTaggart (1) and are discussed in O'Connor's reviews $(91,92)$.

IR absorption has been used to determine hfa in which a double bond is present in an allylic position, for the $O H$ absorption peak disappears on treatment with acid (81).

\section{Determination by Titration}

The standard method for hfa is acetylation followed by extraction of the acetate and determination of its saponification equivalent. The difference between this value and that of an unacetylated aliquot gives the number of equivalents of hydroxyl group. In general, saponification equivalents suffer in precision because one must titrate the excess alkali before and after saponification. A more precise method involves passing the saponified solution through an acid cation exchanger (Dowex 50- $\mathrm{H}^{+}$) and titrating the effluent directly with alkali. Thus one aliquot gives the total number of fatty acid carboxyl groups, while the aliquot from the acetylated sample gives the total number of fatty acid and acetate carboxyl groups. The difference between the two values gives the number of acetate groups. Only two titrations, instead of three, are involved in this method.

When large amts of nfa are also present, even this modification is imprecise and one can then make a direct acetyl group determination. Generally this is done by saponifying or hydrolyzing the acetate ester, then steam-distilling the acetic acid, and titrating the distillate. Texts on quantitative organic microanalysis describe such procedures. A high conen of magnesium sulfate in the hydrolysate speeds the distillation of the acetic acid (29).

The fastest version of the acetylation methods involves acid-catalyzed acylation and direct titration of the excess acetylating agent. A recent description of such a method, intended primarily for high mol wt alcohols (55), calls for a mixture of acetic anhydride in perchloric acid, ethyl acetate, and hexane. After $5-10 \mathrm{~min}$, the excess reagent is hydrolyzed with pyridine-W and the acetic acid is titrated visually or potentiometrically. This method does not require removal of nfa, but it does require adjustment of reagent volumes in proportion to sample size if good precision is to be maintained. A microversion of the same basic method is given by Schenk and Santiago (101).

We have used titration with (ethylenedinitrilo) tetraacetic acid to determine the copper content of precipitated $\mathrm{h}^{2} \mathrm{fa}(61)$.

\section{Radiometric Determination}

By forming a specific radioactive derivative of the hfa, one can measure the amt present simply by counting. All that is needed is a knowledge of the specific activity of the derivatizing reagent and a feeling of assurance that the reaction is complete and that the reagent can be removed completely. Tritiumor $\mathrm{C}^{14}$-labeled acetic anhydride is used in this way to determine hydroxysteroids at very low levels (67). The acetylation is generally done in pyridine and the reagents are removed by solvent partitioning and vacuum evaporation. If a liquid scintillation counter is available, counting can be done very simply even when large amts of nfa and other nonhydroxy compounds are present. One should be able to achieve a precision of 1 or $2 \%$. It is not necessary to count the reagent in order to determine its speeific activity: simply acetylate a known weight of a pure standard, such as cholesterol, and measure the activity of the product. The calculation (for a monohydric alcohol) is :

$$
\frac{\text { micromoles unknown }}{\text { epm of unknown }}=\frac{\text { micromoles standard }}{\text { epm of standard }}
$$

Incidentally, if the hfa is first isolated chromato- 
graphically and weighed, its mol wt (or equivalent weight) can be determined by this method.

A potentially valuable variation on the acetylation method of radiometric determination has been described by Karmen et al. (58). A known weight of a standard hydroxy compound is added to the impure unknown (hydroxysteroid) and the mixture is acetylated with labeled anhydride. A portion of the esters is then subjected to GLC and the peaks (including the peak from the standard) are collected and counted. Comparison of the total activities and weight of standard yields the original amt of the unknown. The method allows determination of several hydroxy compounds in a single mixture, does not require uniform response by the GLC detector, and does not require detectable weights, since nonradioactive acetylated carrier can be added after the acetylation step.

Another radiometric approach is the formation of tritium-labeled methyl esters (from dry $\mathrm{HCl}$ in labeled $\mathrm{M})$, followed by $\mathrm{TLC}$, elution of the hfa spot, and counting. This is a very sensitive method; visualization can be aided with carrier. Unlike the acetylation methods, this one allows determination also of the nfa and any other fatty acids that can be separated on the plate.

\section{Other Methods}

The researcher dissatisfied with the methods described above can consider other methods which have been used for compounds containing hydroxy groups. Active hydrogen determinations should be useful with hfa esters as long as peroxidized esters are not present and the sample is bone dry. We have tried measuring the amt of carbon dioxide produced by oxidizing $h^{2}$ fa, but always found high values, apparently due to attack on the solvents (42). Curiously, the solvent blanks were low; I believe the inorganic byproducts from the oxidant catalyzed oxidation of the solvent. Quantitative TLC by the charring method, described by Privett in this Symposium, should be equally applicable to the hfa.

\section{ACKNOWLEDGMENT} Preparation of this paper and presentation of the Symposium talk
were aided by a grant, NB-03192, from the National Institute of Neurological Diseases and Blindness, USPHS.

\section{REFERENCES}

1. Ahlers, N. H. W., and N. G. MeTagzart, Analyst 79,70 (1954). 2. Ahlers, N. H. W., and N. G. MeTaggart, Andyst Hoster, D. C. Lamb and N. Hodgson, Nature $183,996(1959)$.

3. Barker, S. A., A. B. Foster, D. C. Lamb and I. M. Jackman, Nature 184, 634 (1959).

4. Barrett, C. B., M. S. T. Dallas and F. B. Padley, JAOOS 40 $580^{\circ}(1963)$.

5. Bergström, S. F. Dressler, R. Ryhage, $B$. Samuelsson and J. Sjovall, Arkiv Kemi $13,563(1962)$ iohem. Biophys. Res. Comm. 7 , $337^{\circ}(1962)$

7. Blickenstaff, R. T., J. R. Schaeffer and G. O. Kathman, Anal. Chem. 26, 746 (1954)

8. Bu'Lock, J. D., E. R. H. Jones and P. R. Leeming, J. Chem. Soc. $-1097(1957)$

9. Carroll $\mathrm{K} . \mathrm{K}$. J. Lipid Res. 2,135 (1961)

10. Carroll, K. K., J. Lipid Res. 3,263 (1962)

11. Carter, S. R., and J. A. V. Butler, J. Chem. Soc. 125, 963 (1924)

12. Christie, W. W., F. D. Gunstone and H. G. Prentice, J. Chem Soc. -5768 (1963)

13. Colas, A., and A. Lopez, J. Lipid Res. 1, 486 (1960)

14. Critchfeld, F. E, and J, A, Hatchinson, Anal. Chem. 32, 862

(1560) Davies, W. E., Y. Kishimoto and N. S. Radin, Unpublished work. 16. Davies, W. E., and N. S. Radin, Unpublished work.

17. Davis, S. B., E. A. Conroy and N. E. Shakespeare, JAOCS 72

18. deVries, B., JAOOS 40,184 (1968)

19. Diamond, M. J.. R. E. Knowles, R. G. Binder and I. A. Goldhat J JOCS ot 490 . 1964$)$

20. Dixon, J. S., and D. Lipkin, Anal, Chem, 26,1092 (1954)

20. Dixon, J. S., "and D. Lipkin, Anal, Chem. 26, 1092 (1954) Co.. New York, 1960, pp. 203-206.

22. Downing, D. T., Australian J. Ohem. 14, 150 (1961).

23. Downing, D. T., Ret, Pure Appl. Chem. 11, 196 (1961) Chem, 18,80 (1960).
25. Duncombe, W. G., Biochem. J. 88, 7 (1963).

26. Elderfield, R. C., and F. W. Short, in "Heterocyclic Compounds," edited by R. C. Elderfield, John Wiley \& Sons, Ine., New York, 1957, Fol. 5, p. 29.

27. Waziov, V, I and Z. I. Torgashina, J. Gen. Chem. (U.S.S.R.) 28. Frankel, E. N., D. Q. MeConnell and O. D. Evans, JAOCs 30 , $297(1962)$.

29. Friedemann, T. E., J. Biol. Chem. 123, 161 (1938).

29. Friedemann, T. E., J. Biol. Chem. 128, $161(1938)$. 1808 (1959).

31. Fulco, A.J. and J. F. Mead, J. Biol. Chem. 236, 2416 (1961).

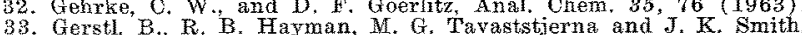

experientia $18,131(1962)$.

34. Glaser, A., G. Grímmer, E. Jantzen and H. Oertel, Biochem. Z $336,274(1962)$.

35. Goddu, R. F., N. F. LeBlanc and O. M. Wright, Anal. Chem. $27,1251(1955)$

36. Goldfine $\dot{\mathrm{H}}$, and K. Bloch, J. Biol. Chem. 236, 2596 (1961).

37. Gorin, P. A. J., J. F. T. Spenser and A. P. Tulloch, Can. J. Chem. $39,846(1961)$

38. Green, K., and B. Samuelsson, J. Lipid Res. 5, 117 (1964).

38a. Gunstone, F. D., and P. J. Sykes, J. Chem. Soc. $-5050(1960)$

39. Gutnikov, G. and G. H. Schenk, Anal. Chem. 34, 1816 (1962)

40. Hagemeyer, H. J., Jr, and D. C. Hull, Ind. Eng. Chem. 41,

$2920(1949)$

41. Haira, A. K., and N. S. Radin, J. Lipid Res. 3, 327 (1962),

42. Harra, A. K., and N. S. Radin, Unpublished work.

43. Hakmori, S., J. Biochem. 55, 205 (1964).

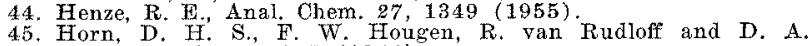

Sutton, J. Chem. Soc. - 777 (1954).

46. Horn, D. H. S., and Y. Y. Pretorius, J. Chem. Soc-1460

47. Horrocks, L. A., and D. G. Cornwell, J. Lipid Res. 3,165 (1962).

48. Hongen, F. W.; Biochem. J. $59,302(1955)$.

49. Houk, A. F. H. J. Pharm. Sci. 52, 738 J 1963$)$. 32,132 (1955).

50. Tnouye, Y., M. Noda and O. Hirayama, JAOCS 32,132

52. Jantzen, E., and H. Andreas, Chem. Ber. 92, 1427 (1959).

52. Jantzen, E., and H. Andreas, Chem. Ber, 92, 1427

54. Johnson, D. P., and F. E. Critehfield, Anal. Chem. 32, 865 $(1960)$

55. Jordan, D. E. JAOCS 41,500 (1964).

56. Kabara, J. J, Anal. Biochem., in press. $31,375(1959)$.

57a. Kaneshiro, T., and A. G. Marr, Biochem. Biophys. Acta 70 $271(1963)$. 58 . Karmen, A., I. McCaffrey and B. Kliman, Anal, Biochem. 6
31 (1963).

59. Kishimoto, Y., and N. S. Radin, J. Lipid Res. 1, 72 (1959).

60. Kishimoto, Y, and N. S. Radin, J. Lipid Res. 1, 79 (1959)

61. Kishimoto, Y., and N. S. Radin, J. Lipid Res. 4, 130 (1963).

62. Kishimoto, Y., and N. S. Radin, J. Lipid Res. 4, 437 (1963).
63 . Kishimoto, Y., and N. S. Radin, J. Lipid Res. 5, 94 (1964).

64. Kishimoto, Y., and N. S. Radin, Unpublished work.

65. Kitagawa, T, M. Sugai and $F$. A. Kummerow, JAOCS 39,217

(1062)

66. Kienk, Fi, Z. Physiol. Chem. 166, 268 (1927),

67. Kliman, B.. and R. E. Peterson, J. Biol. Chem. 235, $1639(1960)$

68. Kuemmel F Anal Chem 34,1003 (1962)

69. Lakshmanan, C. M., and $G$. S. Laddha, JAOCS 37, 466 (1960)

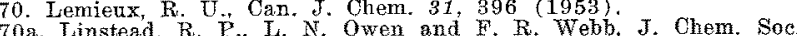

70a. Linstead,

71. Mangold, H. K., JAOCS 38,708 (1961)

72. Mangold, H. K., and R. Kammerreek, Chem. Ind. (London)-

1032 (1961). K. S., in "Fatty Acids," edited by K. S. Markley,

Interscience Publishers, Inc., New York, 1960, pp. 65-88, 183-192. 74. Matic, M., Biochem. J. 63, 168 (1956).

75. Milbum, A. H., and E. V. Truter, $\dot{f}$. Apol, Ohem. 12, 156

$(1962)$.

76. Misiow, K. and S. Bleicher, J. Am. Chem. Soc. 76, 2825 (1954),
77. Miwa, T. K. K. I. Mikolajczak, F. R. Earle and I. A. Wolff, Awal. Chem. 32, $1739(1960)$.

78. Mizukami, S.. and K. Nagata, Yakugaku Zasshi 81, 1285 (1961);

Chem. Abstr., 56,8005 (1962)

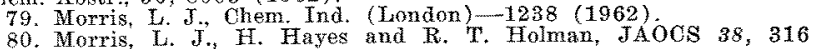
(1961).

81. Morris, T. J., and R. T. Holman, J. Lipid Res. 8,77 (1961).

82. Morris, L. J., R. T. Holman and K. Fontell, JAOCS 37, 323 $1960)$

83. Morris

84. Morris, L. J., R. T. Holman and K. Fontell, J. Lipid Res, \&, 68 (1961)

85. Morrissette, R. A., and W. E. Link, JAOOS 41, 415 (1964)

86. Müller, A, Chem. Ber. 72,615 (1939).

88. Noble, W. R., A. Eisner and J. T. Scanlan, JAOCS 37, 14 $(1960)$.

89. O'Brien, J. S., D. L. Fillerup and J. F. Mead, J. Lipid Res. 5 , $109(1964)$

90. O'Brien, J. S.. and G. Rouser, Anal. Biochem. 7, 288 (1964). 91. OConnor, R. T., JAOOS 33, 1 (1956).

92. O'Connor, R. T., in "Fatty Acids", edited by K. S. Markley, Interscience Publishers, Inc., New York, 1960, pp. 380-498.

93. Okui, S. M. Uchiyama and M. Mizugaki, J. Biochem. 53, 265 $(1963)$.

94. Okui, S., M. Uchiyma and M. Mizugaki, J, Biochem, 54, 536 $(1963)$.

95. Preiss, B., and $\mathrm{K}$. Bloch, J. Biol. Chem. 239. 85 (1964).

96. Radin, N. S. A. K. Hajra and Y. Akahori, J. Lipid Res. 1, 250

$(1960)$.

97. Radin, N. F. B. Lavin and J. R. Brown, J. Btol. Chem, 21\%, 97. Radin
$799(1955)$

98. Ridale V M Anal Chem, 35, 853 (1969)

99. Rouser, G., A. J. Bauman, N. Nicolatdes and D. Feller, JAOCS (1961)

100. Ryhage, R., and E. Stenhagen. J. Lipid Res, 1,361 (1960)

101. Schenk, G. H., and M. Santiago, Microchem. J. 6, 77 (1962)

102. Scheuerbrandt, G., and K. Bloch, J. Biol. Chem. 237, 2064 $(1962)$. 
102a. Schwartz, D. P., O. W. Parks and M. Kenney, Anal. Chem. $34,669(1962)$

103. Schwenk, E., and D. Papa, J. Am. Chem. Soc. 70, 3626 (1948).

103a. Scoggins, M. W., Anal. Chem. 36,1152 (1964).

104. Serck-Hanssen. K., Arkiv Kemi 10, 135 (1957).

105. Serck-Hanssen, K., Chem. Ind 1554 (1958).

106. Skipski, V. P., S. M. Arfin and M. M. Rapport, Arch. Bioehem. iophys. $87,259(1960)$

107. Slepecky, R. A., and J. H. Law, Anal. Chem. 32, 1697 (1960)

108. Smith Jr C. R. T. L. Wilson, E. H. Melvin and I. A. Wolf

Am. Chem Sac $82,1417(1960)$

109. Sreenivasan, B., N. R. Kanath and J. G. Kane, JAOCS 33, 61

$(1956)$

110. Sweeley, C. C. R. Bentley, M. Makita and W. W. Wells, J, Am.

Chem. Soc. 85,2497 (1963).
111. Sweeley, C. C., and E. A. Moscatelii, J. Lipid Res, 1, 40 (1959). 112. Thomas, W. J. O., J. Chem. Soc.-3307 (1951) (1964).

114. Vandenheuvel, F. A., Anal. Chem. 36, 1930 (1964)

115. Vioque, E., and R. T. Holman, JAOCS 39,63 (1962).

116. Wagner, $H_{2}, J .-D$, Goetschel and $P$. Leseh, Helv, Chim, Acta $46,2986(1963)$

117. Weaver, N., J. H. Law and N. C. Johnston, Biochim. Biophys. cta $84,305(1964)$.

118. Wood, R. D., P. K. Raju and R. Reiser, JAOCS 41, 36A (1964).

119. Yokoyama, S., and T. Yamakawa, Jap. J. Exp. Med, 34, 29 (1964).

\section{The Metabolism of Polyenoic Fatty Acids}

\section{E. KLENK, Institute of Physiological Chemistry, University of Cologne, Cologne, Germany}

\begin{abstract}
Feeding experiments with $\mathrm{C}^{11}$-labeled and unlabeled unsaturated fatty acids have been used to study the possible routes of formation of the $\mathrm{C}_{20^{-}}$and $\mathrm{C}_{22}$-polyenoic fatty acids of rat liver phosphatides. The acids of the palmitoleate, ole. ate, linoleate, and linolenate types (considered on the basis of the position of the double bond closest to the methyl end) are apparently formed from the $\mathrm{C}_{16}$ and $\mathrm{C}_{18}$ unsaturated acids of the corresponding types. The results rule out possible transformations of the $\mathrm{C}_{20^{-}}$and $\mathrm{C}_{22}$-polyenoic acids from one type to another, and demonstrate the exclusive introduction of new double bonds toward the carboxyl group. Isomers of linoleate or linolenate in which the double bonds were shifted by one carbon atom toward the carboxyl or methyl groups were incorporated into the phosphatides only to a negligible extent in the form of polyenoic acids.
\end{abstract}

FIG. 1

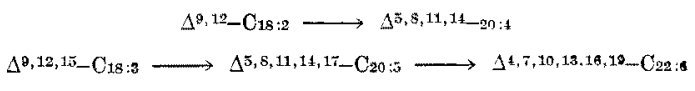

$$
\begin{aligned}
& \Delta^{0}-\mathrm{C}_{18: 1} \longrightarrow \Delta^{5,8,11}-\mathrm{C}_{20}: a
\end{aligned}
$$

FIG. 2

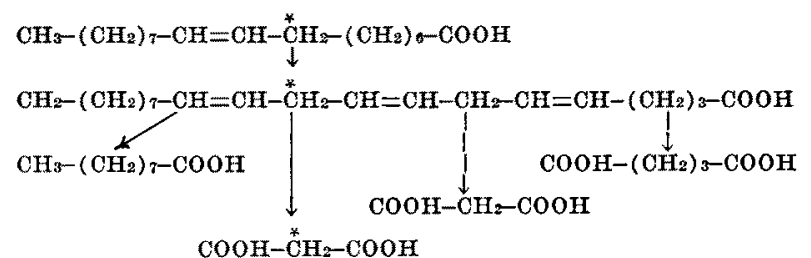

OST OF THE $\mathrm{C}_{20^{-}}$and $\mathrm{C}_{22}$-polyenoic fatty acids $\mathbf{V}$ occurring in the phosphatides of the higher animals have their first double bond (counted from the terminal methyl group) in the 6 or 3 position. Linoleic acid, the $\mathrm{C}_{18}$-diene, has its first double bond in the 6 position and linolenic acid, the $\mathrm{C}_{18}$-triene, has its first double bond in the 3 position. Thus the larger polyenoic acids may be considered as being either linoleic or linoleic acid types (Fig. 1). The latter acids have been shown to be precursors of the longer acids, undergoing chain-elongation and introduction of new double bonds (1). The new double bonds are directed toward the earboxyl group and maintain the divinyl-methane rhythm. The enzyme system carrying ont these reactions is found in the liver microsomal fraction, as shown by Stoffel (2).

Besides the long polyenoic acids of the above two types, we have found in phosphatides a smaller amt of $20: 3^{5,8,11}$, with a structure of the oleic acid type, the first double bond being in the 9 position $(3,4)$. It has been known for some time that a $\mathrm{C}_{20}$-trienoic acid accumulates in liver lipids of rats on a fat-free diet. Mead and colleagues (5) have identified this acid as being $20: 3^{5,8,11}$ and have given evidence for its synthesis from acetate $(6)$. The reasonable assumption has been made that stearic and oleic acids are intermediates in the biosynthesis. We have given direct evidence for the transformation of oleic acid into this triene by feeding $8-\mathrm{C}^{14}$ oleate to fat-deficient rats $(7)$. The labeled fatty acid was made by total synthesis. Both the $\mathrm{C}_{20}$-triene and arachidonic acid were isolated from liver. The trienoic acid had a specific activity of $8730 \mathrm{dpm} / \mathrm{mg}$ and $96 \%$ of its radioactivity was located in the malonic acid obtained by oxidative ozonolysis. The nature of the reactions is illustrated in greater detail in Figure 2.

On the other hand, the $\mathrm{C}_{20}$-tetraenoic acid of the linoleic acid type, arachidonic acid, had a specific activity of only $115 \mathrm{dpm} / \mathrm{mg}$. Thus only the $20: 3^{5,8,11}$

FIG. 3

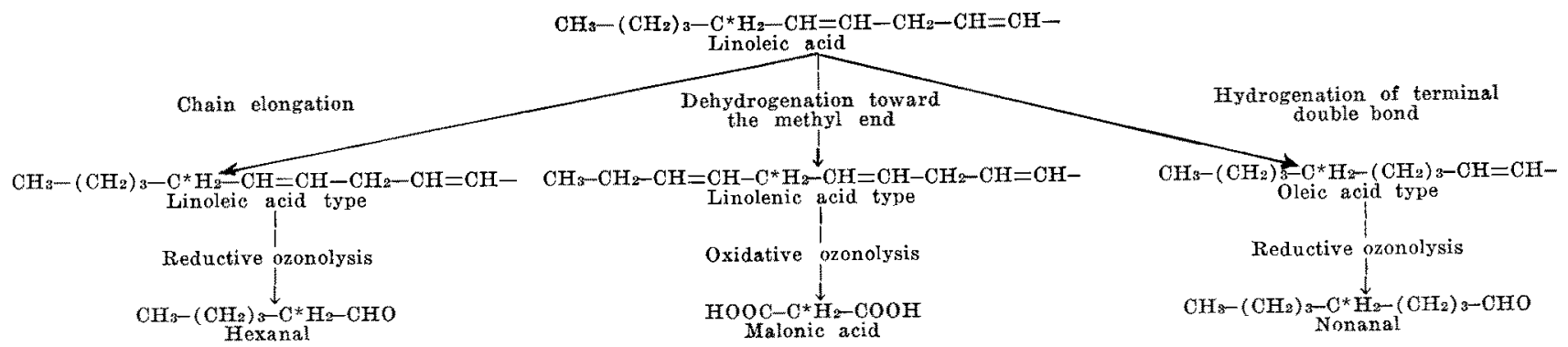

